\title{
Optimising Student Learning on International Placements in Low Income Settings: The Contribution of Cultural Brokerage
}

\author{
Helen Louise Ackers, James Ackers-Johnson, Anya Ahmed, Natalie Tate \\ University of Salford, Salford, Greater Manchester, UK \\ Email: H.L.Ackers@salford.ac.uk, J.Ackers@salford.ac.uk, a.ahmed@salford.ac.uk, N.J.Tate@edu.salford.ac.uk
}

How to cite this paper: Ackers, H.L., Ackers-Johnson, J., Ahmed, A. and Tate, N. (2019) Optimising Student Learning on International Placements in Low Income Settings: The Contribution of Cultural Brokerage. Open Journal of Social Sciences, 7, 311-327.

https://doi.org/10.4236/jss.2019.73026

Received: November 30, 2018

Accepted: March 18, 2019

Published: March 21, 2019

Copyright $\odot 2019$ by author(s) and Scientific Research Publishing Inc. This work is licensed under the Creative Commons Attribution International License (CC BY 4.0).

http://creativecommons.org/licenses/by/4.0/

\begin{abstract}
This paper challenges the assumption that student visits to low resource settings inevitably promote the acquisition of cultural competence. Much of the literature advocating the expansion of such "exposures" lists numerous positive outcomes with an emphasis on "cultural learning". With important exceptions, the concept of cultural learning remains uncontested, nestling in the fluffy haze of an inherently benevolent multi-culturalism. The emphasis in current research is on "learning" or "competency" at the expense of definitional clarity around the concept of culture itself. This results in a tendency to overemphasise (and essentialise) difference rather than commonality and conflates cultural learning with narrow (stereotypical) concepts of race, ethnicity and religion. The paper discusses the experiences of students undertaking placements in Uganda through Knowledge for Change, a UK charity hosting the Ethical Educational Placements project.
\end{abstract}

\section{Keywords}

Cultural Competence, Cultural Learning, International Student Placements, Global Health Education, Uganda

\section{Introduction}

There is a growing interest in the role that international placements, especially those in Low and Middle-Income Countries (LMIC's) can play in student and professional learning. Those studies that have addressed the outcomes of such placements typically identify "cultural" learning as a key component of this. In the Royal College of Midwives' Global Engagement Survey, for example, 81\% of respondents reported gains in "cross cultural competence" [1]. In our own sur- 
vey of students completing placements, $97 \%$ reported that the placement had a strong or very strong (79\%) impact on their cultural awareness [2]. These findings are echoed in many other studies [3] [4] [5] [6]. Great attention is paid in this literature to the accompanying concept. Lough et al. [7] distinguish, "cross-cultural competence, intercultural effectiveness, intercultural competence, intercultural understanding and multicultural competence". Sargent et al. [8] with reference specifically to nursing, suggest that "cultural competence" (the most commonly used construct) is a composite outcome of cultural awareness, cultural knowledge, cultural skill, cultural encounter and cultural desire. Echoing the language of behaviour change theories, this approach suggests that when knowledge is combined with a willingness to learn, encounters (in the form of international placements) can play a critical role in building cultural competence. Rather than dwell on the distinctions between competence, knowledge and awareness, this paper focuses on the common denominator; the "elusive concept" of culture itself [9] in the context of our on-going action-research on placement learning.

The literature on cultural competence spans a continuum. At one end of this lies work that links cultural knowledge directly, if implicitly, with those aspects of diversity linked to race, ethnicity and religion. An example of this approach is cited in Cunningham et al's work on mental health amongst Afro-Caribbean children in the US. The authors explain that, "within the field of mental health services, the term 'cultural competence' generally refers to the ability to understand and function effectively in meeting the needs of minority populations" [9]. Leishman [10] argues that "immigrants" and refugees in Scotland have "substantially different health care needs" deriving not from their experiences of oppression or migration but from their "cultural backgrounds" [10] and nurses require cultural competence to manage these effectively. Another example can be seen in Elliot's paper on "cultural competent learning experiences for Aboriginal students" which makes a strong case for "increasing the numbers of Indigenous people working in healthcare" [11]. Whilst we would support measures to increase workforce diversity, we are not convinced that "ethnic matching" on the grounds that "Aboriginal health providers are more often acceptable to the community" [11] is either achievable or desirable. Nevertheless, this conflation of culture with ethnicity is echoed in the marketing of voluntourism by Gap Year Companies [12] [13] and in the motivations expressed by students applying for placements.

At the other end of the continuum, Garneau and Pepin propose a "constructivist definition" of cultural competence. Their paper opens with the statement that, "In nursing education most of the current teaching practices perpetuate an essentialist perspective of culture" [14]. Cultural competence in their view is about the development of critical, reflective practice to enable nurses to play a role in the reduction of health inequalities. As such, it "encompasses diversity that can assume many forms in society-such as age, gender, sexual orientation, 
or socio-economic status-and is not limited to race and ethnicity" [14]. The authors argue that there are two opposing views of culture; the essentialist view and the constructivist view. The former has the tendency to equate culture narrowly with ethnicity with an emphasis on the differences between people. This approach also assumes that ethnicity is the most defining feature of relationships and difference and is homogenous and stable over time. Simpson uses the concept of "homogenised essentialism" to capture the risks associated with these over-simplified us-and-them; needy-helper dualisms [12]. The constructivist perspective understands culture as "the product of social constructions; a dynamic relational process of shared meanings" [14]. Attempts to understand how social positions overlap have previously been framed in terms of intersectionality [15] [16] [17] [18]. So, a health worker may be both Ugandan and female, for example, or a British student may have diasporic connections. ${ }^{1}$ These complexities influence the way students on placement position themselves in relation to the people they encounter [19].

Crabtree et al. explore the processes of student learning in "unfamiliar cultural contexts" and argue, in a similar vein, that cultural competence is as much about recognition of power differentials and the "superior positioning" or "othering" of western paradigms as it is about the specifics of cultural difference [20]. In this frame, humility rather than the acquisition of substantive "cultural" knowledge is the goal. This conceptualisation of culture resonates far better with the 5 core "Global Health Competencies" outlined by Dias et al. [21]. In this schema, culture is integrated within Competency 1: "Diversity, Human rights and Ethics" locating culture firmly within an understanding of diversity in the widest possible sense linked to a human rights framework and principles of neutrality, impartiality and medical conscience [21]. The ultimate objective is to "respect the rights and equal value of all people without discrimination and provide compassionate and respectful care for all patients" [21].

Interestingly the interviews with professional volunteers in Uganda [3] suggested that the most valuable "cultural learning" was focused not so much on learning about exotic or different others but on learning what it felt like to be "other". One of the respondents described her experience as follows:

Certainly, in the UK you're kind of aware of all the cultural differences and you "do" equal opportunities but until you' re actually in a place where you' re the outsider, you don't realise how much it impacts [3].

We would argue that whilst exposure to "other cultures" will contribute to learning this will only lead to improved competence and practice if this learning supports a process of ever-emerging humility and awareness that, ultimately, we cannot achieve complete "cultural knowledge". Every person is an individual and has a right to be treated as such. In that respect, learning what it feels like to be an "outsider" or "other" is perhaps the most significant.

${ }^{1}$ For a more detailed discussion of intersectionality and the linked concept of translocational positionality see [17] [19]. 


\section{Organisations and Culture}

A search for the term "culture" in the context of the UK's National Health Service opens a Pandora's box of studies focused on organisational culture and its relationship to core values such as respect, compassion, care and patient safety. And yet, when we review papers on placement learning in LMICs the emphasis is immediately on the more familiar association between culture and ethnicity/religion. The reasons for this are unclear. Perhaps this reflects the association of such placement locations with exoticism and difference rather than the more mundane commonalities associated with organisational culture in public sector organisations across the world. Perhaps the emphasis on travel distracts us from these dimensions of culture to focus on the more exotic differences between "peoples"?

Although some of the more insightful studies make passing reference to health systems or the wider societal and political context within which placements and cultural learning takes place very few specifically refer to the role of organisations. This contributes to yet another stereotype; that health systems in LMICs are monolithic. Concepts of welfare pluralism or the "mixed economy" have been used for many years to characterise the complexities and inequalities associated with contemporary health systems [22] [23] [24]. Welfare diversity is the corollary of human diversity and inequality and, contrary to popular media portrayals, the concept applies just as much, if not more, to low and middle-income countries. Countries like Uganda have burgeoning private sectors in health both in the "for-profit" and "not-for-profit" sectors (heavily subsidised by international Aid). Many of the wealthiest people in Uganda also source their healthcare internationally. The so-called "universal" public health system in Uganda is best characterised as a residualised welfare system; at best an ineffective stigmatised "safety-net" for the countries' poor. In contrast with the UK's NHS, very few Ugandan health workers would consider using public health services themselves contributing to a culture of "othering" within the organisation as a whole. As an organisation focused on health systems change and improving access to quality healthcare for the poorest, Knowledge for Change is committed to working in the public health sector. This is where we place our students, and this is the organisational context within which they experience "culture" [25].

Hofstede defines organisational culture as "the collective programming of the mind which distinguishes members of the organisation from another" [26]. In keeping with the point about essentialism above, he reminds us that organisations are not homogenous and can be composed of various sub-cultures which may be mutually antagonistic. With specific reference to organisational culture in health care, Davies et al. point to the level of cultural diversity both between and within health providing organisations and the impact of counter-cultures that may impede change [27]. Carney refers to the lack of definitional clarity on the concept of culture in healthcare organisations suggesting its meaning varies from one situation to another [28]. Citing Deal and Kennedy, she describes cul- 
ture as a driver of norms and the "way of doing things around here" [29]. Furthermore, "values are the explicit and implicit elements of the care culture that serve to determine the individual's action system" [30]. The influential Kings Fund report, "Caring to Change" immediately identifies "compassion as the core NHS cultural value" and the importance of organisational "socialisation" to the embedding of this value and to innovation in health care more generally [31]. This emphasis on organisational culture as a key target for change in the NHS is rarely echoed in the literature on global health. A recent paper by Mbau and Gilson is an important exception. The authors reflect on the failure to achieve health systems change in LMICs pointing to the "dearth of empirical literature around organisational culture" [32] as a potential barrier to reform. They note that organisations are themselves embedded within wider society and societal values and indicate the potential impact of hierarchy and power relations on those people employed within them.

\section{Methods}

The research presented in this paper builds on ten years' experience of ethnographic action research in Uganda. Specifically, the research is based on three linked studies. The first action-research study involved the design and evaluation of the ethical educational student placement scheme. The study funded over 80 students to conduct a four-week placement in Uganda and combined analysis of qualitative data including observational research, pre and post placement interviews and focus groups with the students as well as documents such as student applications, weekly and post-placement reports. This study also drew upon an online survey based on the student overall experience [2]. ${ }^{2}$

The second study is Tate's doctoral research, which builds on this work and uses ethnographic and longitudinal methods to specifically capture the process of cultural learning amongst a cohort of midwifery students. The study utilises data taken from the student's initial application forms, pre-placement interviews, followed by two ethnographic field trips (one month each) to Uganda with 10 students, in July 2016 and March 2017 (5 students per trip). A further post placement interview with each student was conducted 12 months after the placement end date. The qualitative data from the two field trips included observational research, in-depth interviews and focus groups. The approach taken for this study allows the research to illuminate and track the student placement experience as well as explore any impact from initial application through to 12 months post-placement ${ }^{3}$.

The third study focuses on respectful care in Ugandan public health settings. Using qualitative data analysis, the research explores mothers and midwives' understandings of the concept of respectful care and their experiences of the care they have received or delivered. The study involved 64 in depth qualitative inter-

${ }^{2}$ This study took place in 2016/17 and included pre-during and post placement interviews, observational research and an on-line survey. Full details of the methods are contained in [2].

${ }^{3}$ Tate's ethnographic doctoral study is due to finish in 2019 . 
views and three focus groups with health workers and mothers to assess their experiences of maternity care. ${ }^{4}$ The findings have been analysed thematically using NVIVO10. Each study has received ethical approval from the University of Salford and Mountains of the Moon University, Uganda.

\section{Results}

Combining our data from the three studies has stimulated us to reflect on the relationship between culture and compassion in the placement locations and the influence this has on student learning. We would argue that much of the learning that students attribute to culture is as much about the organisational cultures associated with Ugandan public health facilities as it is about culture in general. One of the topics that emerge with some frequency in the interviews, perhaps reflecting K4C's focus on maternal and newborn health, is the perceived relationship between "culture" and bereavement care. The following case is quite typical. Lucy, a qualified nurse undertaking a post-registration midwifery program talks, in her pre-departure interview, so before visiting Uganda, about what she hopes to gain from the experience;

"I want to learn about another culture, another health care system [...] I am interested in new born bereavement care, $P$ ve dealt with it a few times here in the UK and the care given is to a really high standard. I would like to see how they do things over there".

At this point Lucy presents herself as a learner keen to gain knowledge from Ugandan health workers about their approach to bereavement care. The interviewer follows up with:

"What do you mean about bereavement care being different in Uganda?"

"I think they think over there that when a child has died at birth or shortly after that not seeing the child and not making memories with that child is better than seeing it. Because you can't process the bereavement, but we know in this country that that doesn't work."

It is interesting to see how, in the last point Lucy shifts from a concept of herself as going to learn to one of imparting superior evidence-based practice and a shocking lack of humility.

She goes on to say,

"I think they cope with [losing a baby] over there because it is a lot more common, culturally they' ve found a way to keep managing it".

Interviewer. "So when you talk about culture influencing this, what do you mean?"

"I think because they have a lot more children, and they don't have the same health care and they also have a lot more loss. So, they're taught to be quite strong as women, and I think in their culture they are strong as women and they birth on their own".

It is difficult to tell from the narrative whether the respondent is referring to

${ }^{4}$ This study involved 64 interviews with mothers and health workers in 2017 and is reported in [33]. 
health workers or women in general here. The final comments would suggest she is talking about the experiences of (all) women in Ugandan society and that it is their culture, rather than the lack of respectful and effective services, that make women strong enough to birth without support. Lucy may be surprised to learn that the private ward at the National Referral Hospital in Uganda has a caesarean section rate of over $60 \%$ [34]. Jenny makes a similar observation, again before she goes on placement, and like Lucy, uses a form of words suggesting she is heading out to Uganda expecting to impart her superior knowledge rather than to learn as such:

"I d like to make sure the woman has the option to spend time with their baby if they don't make it. Pve heard that they take the baby away straight away without giving mum a chance to see it. We know for long term coping and bereavement that it's best to spend time with the baby so I want to see how I can help there."

It is interesting to reflect on the fact that both Jenny and Lucy had quite clear views about how bereavement is experienced and managed in Uganda even before they left the UK. But what are the sources of such views? Student applications often refer directly to the influence of media campaigns. Asked why she had expressed an interest in the placement Lucy replies:

"P ve just always wanted to do something like this, like since I was little. I always used to watch Comic Relief and all that and want to help".

Research by Voluntary Service Overseas on the impacts of stereotypical portrayals of Africa found that " $80 \%$ of the British public strongly associate the developing world with doom-laden images of famine, disaster and Western aid" [35]. The VSO report blames UK media for creating the widespread perception that people in the developing world (particularly African countries) "are victims, less than human and inferior" [35]. In a similar vein, [36] argues that Africa is often portrayed as an homogenous entity comprising uncivilized and heathen peoples who are culturally, intellectually, politically, and technically backward or inferior. Seay and Dionne [37] suggest that this leads to misinformation, stereotyping, validation of white privilege and excessive fear of foreigners. In theory, a placement presents a unique opportunity to challenge stereotypes and build more meaningful awareness of societies and health systems. On the other hand, there is a risk. Unless such processes are managed carefully and students are adequately prepared and supervised, rather than challenging such stereotypes, LMIC placements may simply reinforce them. As Crabtree et al. point out, immersion in another country (if it even is immersion) does not necessarily contribute to cultural competence [20]. Even in the context of hard-core poverty, "students can fail to pick up on the differing cultural context and social policy drivers in place" [20]. Of greater concern, the returning "pioneers" may exude a heightened sense of "cultural competence" authenticated and validated by their direct experience. This was almost certainly the case with Lucy and Jenny both of whom had met student nurses returning from placement who had experienced bereavement in Uganda. Another student makes a similar observation in a 
post-placement interview illustrating the potential risks associated with this type of unmediated learning.

"There is no compassion over there and so that was one of the hardest things coz when one of the babies died, and the doctors saw them dead, there was no grief, no compassion, no emotion, it was just really cold".

This comment, made following her return to the UK, is an example of the dangerous and essentialising generalisations, attributed to "culture" that students may come home with and disseminate with the authority of "experience." In this context Crabtree et al. suggest that "peer support of other students ... can generate unhelpful dynamics" [20]. Certainly, our ethnographic research with students on placements as a group would support this contention, that in the absence of a more experienced cultural broker/mentor, students, often distressed at their experience, use social time to discuss and often reinforce stereotypes. The influence of such discussions and the ability to challenge strongly held views depends very much on power dynamics within the student group and the presence of confident cultural brokers.

Another very common response from students concerns the relationship between time-keeping and culture and the impact on care. Pamela expressed an excitement in her pre-departure interview about the opportunity to learn about different cultures (presumably implying an interest in culture-as-ethnicity). The tone of an interview during her last week in Uganda indicates a growing frustration with this aspect of learning:

"Grappling with the culture has been the hardest thing I had to deal with. I know so much more about it now than I thought I did three weeks ago".

Pamela goes on to give an example of her "cultural" learning.

"She (Ugandan midwife) basically just walked off because it was quiet, we reckon she went to the shops to be honest. I mean it was quiet, but you don't just leave do you? I know culturally it's different but that's just basic midwifery, you don't just leave. I think in their culture it's just about getting home, but I felt the patient should have stayed overnight-she wasn't well and they shouldn't have let her go."

Pamela is clearly concerned that a patient was discharged, in her view, prematurely and allowed to travel home on the back of a motorcycle. She attributes this behaviour, in terms of time-keeping and absenteeism, to culture but what does she mean by "their culture"-who are we actually talking about? Ugandan people as a whole, midwives as a sub-culture or the staff in that specific facility? In this case Pamela was witnessing a very common situation in the Ugandan public sector. Health worker absenteeism and poor attitudes to time-keeping and a desire to "clear the lines" and leave the facility are very typical behaviours. Our own research has evidenced these behaviours from the perspective of Ugandan health workers themselves as indications of a culture of disrespect [33]. On that basis we do not doubt that this situation took place, but it is important that students understand the factors influencing health worker behaviour and what culture means in this context. The association of a lack of compassion or 
professional negligence with national as opposed to organisational culture is very common in student narratives:

"I was smiling at her and telling her she was doing so so well but (Ugandan midwife) was just so stone faced like she had seen it a thousand times. I know she has but she should be encouraging her and telling her she's doing really really well, praising her and cheering her on. It's like there is no culture for praising women, they are just in and out, job done, see ya."

In this example the student has "learnt" that the failure to praise and encourage women during labour is part of Ugandan culture with an inference that this behaviour is endemic. In another case, the student appears to suggest that this "normality" of disrespectful behaviour somehow signifies a lack of intentionality or responsibility because it is "cultural". Put crudely, "they" don't know any better;

"Sometimes it's different cultures you know the way they deal with things. Like sometimes people don't necessarily mean to be rude or awful, it's just how they've spoken most of their life you know or how they speak to people, and nobody's ever really turned around and said: 'Oh, well you shouldn't do that, you shouldn't say that to people".

Does this imply that disrespect is a deep-seated aspect of national culture in Uganda? Certainly, this interpretation does not sit alongside students' cited experiences of the very welcoming Ugandan public during their stays [33]. It is very common for students to come away with the sense that Ugandan health workers "didn't really care". The following student links this apparent lack of compassion to culture;

"Their culture tells them that they shouldn't really show that much emotion especially in public. Like when they're in labour, you shouldn't be making noises, how they are so silent is beyond me but, I think obviously if they've been brought up to be that way you know it's normal for them, but then outsiders coming in and seeing that you think, do the [health workers] not care at all?"

In the first instance, the student suggests that it is culture that leads women to know not to make noise and that this cultural pressure leaves little room for individual choice or agency. Then, secondly, she infers that this same-or is it another form of culture-normalises a lack of care amongst health professionals. Without constant support, superficial impressions of Uganda/Ugandans and the Ugandan health care system, compounded by a lack of understanding of global and structural inequality and humility-encourages students to homogenise their hosts as foreign and "other". Others construct "Ugandan-ness" with what can be interpreted as a range of (contested) characteristics and emotions [38], or a homo nationalis [19] [38]. The student in the next example shows an awareness that culture is nuanced and not all health workers are equally disrespectful. Once again her language immediately suggests that she perceives her role as one of imparting superior knowledge rather than learning as such. The interesting thing about this example is that, not only is culture associated with poor attitudes towards patients, it is also associated with resistance to change: 
"The [Ugandan health workers] were really fascinating and so keen to learn. The main thing we noticed was the culture side of it-the attitude, so like a lot of the newer people coming through were brilliant and we couldn't fault them. One of the sisters we wanted to come and work over here, she was so good. However, there were others who just didn't want to change and their attitude towards patients was appalling. It was not the fact they didn't have resources, it was more that they didn't want to change what they were doing."

Once again, the observations made by this student come as no surprise to us; disrespect and verbal abuse are commonplace in Ugandan public facilities and we have struggled over the past decade to understand the relationships between knowledge acquisition and behaviour change [25]. These issues are incredibly complex, and experts have failed to adequately theorise behaviour change in health care. It is interesting that this student realised that importing new knowledge in itself could not bring about change; the Ugandan public health system as a whole is not receptive to new knowledge and displays marked resistance to change. But it is all too easy to conclude that this is simply a question of culture. The student is doubtless aware of many examples of the gap between knowledge and behaviour change in the NHS but is not making this link. Perhaps the fact that she is in Uganda has distracted her from this more mundane association?

An interview with a local (male) health worker suggests that disrespect is not endemic in Ugandan health care and reflects in large part not Ugandan culture, as such, but specific organisational cultures:

"I think in the public sector, it may be a number of factors ranging from administration to attitudes of the health worker and maybe also the number of patients someone is seeing".

Interviewer: "Why would someone's attitude be different in a public facility?"

"Someone looks at people in a different way as if they cannot do anything [ to challenge their care] and will not give enough care but when you are in a private facility then someone will know, 'Maybe I am going to be reported? There is a lot of bureaucracy in a public facility so if you were to report someone it will take a lot of time. Because who do you report to? It is really hard and to chase that person if someone has done wrong, it is a very long system".

Interviewer. "So it's not just that the health workers in a public facility have less-resources, they also have less accountability in a sense that they can possibly get away with worse behaviour?"

"Yah [in private sector] they would be caught. Some people say it may be the salary-that public sector salaries are low-but when you look at mission hospitals-they pay less money. That's why I think it is more attitudes because the poor [patient] is not having power. If the person is some official in the Government, someone gives a lot of care and when you see such people coming, everyone is concerned. You make sure you give enough care. But there are also some good nurses maybe midwives too who feel everyone deserves and has a right to ${ }^{5}$ This work is developed in [33]. 
get good service. Some people get money from patients in public settings like in busy hospitals, they say if you don't give us money we shall not work on you. Ask patients, they will tell you, that if you go here and you don't have money they will not work on you. It's not because of salaries. It's mainly because of the supervision, it's more administrative because they see their supervisors are not really taking action".

The respondent suggests that the behaviour of health workers is quite different in public facilities as compared to private, not-for-profit, facilities where accountability is much higher (and patients pay for their care). He also hints at the pervasive impact of corruption on care. The conversation then turns to consider whether the gender of the health worker, in the same public facility, influences respect. Supported by a female health worker present at the interview, he argues that men are more compassionate and goes on to link compassion with religion:

Female Health worker. "Men (male health workers) show much respect than women".

Interviewer. "Why do you think that is?"

Female Health worker. I think men know women are passing through much pain, that's why they talk politely, show much respect. But a woman would be like, "Me too, I delivered you have to pass through that pain".

Male health worker. "Culturally they know a woman is supposed to go into that pain of delivery, and also when you look at Ugandans, they have taken more of Christianity and I think in Christianity, they say a woman has to face this".

We have cited this at some length to illustrate the resonance of this analysis of health worker behaviour with Garneau and Pepin's constructivist approach to culture and the complex web of power relations and inequalities that form the context within which our students learn [14]. Sargent [8] identifies the process of "cultural encounters" as one component of cultural competence - which on its own may lead to essentialism and stereotyping. Extensive research on theories of learning ${ }^{6}$ has emphasised the importance of a "More Knowledgeable Other" [39] in a mentoring relationship to impart knowledge but also, critically, to mediate the learning process. It would be unthought of to expect a student to learn a clinical skill in the absence of such a presence and yet we expect cultural learning to take place through unmediated absorption. The Ethical Educational Placement scheme managed by K4C supports a much higher level of support for students which includes an induction process prior to departure and on arrival plus weekly de-briefing meetings and reporting. Perhaps most importantly all students are supported on the ground on a daily basis by an experienced Ugandan placement manager and a multi-disciplinary team comprising UK professional volunteers (including members of the Ugandan diaspora) and Ugandan faculty many of whom have spent time in the UK. These actors have an impor-

${ }^{6}$ Vygotsky (1978) argues that when a student is in the "zone of proximal development" (where the potential to learn is very high) the presence of a More Knowledge Other (or more capable peer) providing essential "scaffolding" will optimise learning outcomes [39]. For further discussion of these concepts and their application to student placements see [40]. 
tant role to play in mediating relationships with local health workers and encouraging students to reflect upon and make sense of what they are observing and experiencing and challenge assumptions. In particular, as a project we seek to import values of humility and reflexivity amongst our students. In recent months students on placement in Uganda have expressed concerns about a situation that they have both witnessed and that has compromised their relationships with local midwives. This involves the local midwives completing fake partograms ${ }^{7}$ and, worse still, amending partograms completed by $\mathrm{K} 4 \mathrm{C}$ volunteers and students to make processes look perfect. Lorna, a student on placement, speaks about this during a conversation in the evening:

"They were trying to lie about partograms. I mean you can't just lie; that's awful". Her peer, Susan, replies, "I mean you can understand some of the things they do because that's all they know but false documentation is just really awkward ..."

Unfortunately, this process continues and a post-placement discussion between $\mathrm{K} 4 \mathrm{C}$ staff and a group of returned midwifery students explored the same theme. One student opened the group discussion with the comment:

"I expected mothers and babies to die but not from lack of care; I expected it to be a lack of resources."

At this point the $\mathrm{K} 4 \mathrm{C}$ representative replies: "What do you mean by lack of care?" and the student replies: "The way they talked to women; the way they treated them in labour. At Facility $X$ the midwives were blatantly falsifying records and partograms so they followed the pattern perfectly. They don't care that the documentation is false or that women are in pain. They are like, 'you just have to deal with it'. I realise it's a cultural difference, but they'd go into the ward and just slap or shout at the women". The K4C representative replies: "Do you think that the fact that they are not completing the partogram accurately is because, as individuals, they don't care?" One student responds, "I think the system has made them not care" and another challenges this with, "No, because the attendants (informal carers accompanying patients) with their sisters and daughters were different too; they would withdraw themselves emotionally from the patient as if they can't empathise." A third (more reserved) respondent suggests "is that a cultural way of expressing their care though?"

This scenario illustrates the opportunity for cultural brokerage; the $\mathrm{K} 4 \mathrm{C}$ representative explains in detail the background to the whole partogram issue. We won't cite the extensive discussion that took place at this point but give a flavour:

"What you witnessed here was a health systems problem. We had discussions with (a senior health manager) recently-it is hard to get to the bottom of things in Uganda-but it seems a Belgian NGO has set up a project there based on Results-Based Finance. What you saw in (Facility $x$ ) was the consequence of Aid. After many years of poor outcomes, Aid agencies are now using results-based

${ }^{7} \mathrm{~A}$ partogram or partograph is a composite graphical record of key data (maternal and foetal) during labour entered against time on a single sheet of paper. Relevant measurements might include statistics such as cervical dilation, foetal heart rate, duration of labour and vital signs. 
systems to incentivise staff, in this case to take patient observations and record them. The idea that this can work without massive unintended consequences, is quite frankly absurd. Add to this the complication that Ugandan staff don't want to tell us (K4C) what other NGOs are doing, and you end up in a mess. The partograms contribute directly and significantly to their income and this skews their behaviour."

This discussion illustrates the importance of brokerage, before, during and post-placement in supporting genuine student learning. The point is not to excuse or gloss-over highly problematic behaviour; rather to understand it as a facet of organisational culture reflecting key systems dynamics (subsistence pay and lack of accountability).

The process of completing this review of cultural competence has lead us to propose further strengthening of processes to build in more dedicated time during the induction to cultural learning and, post-placement, to reflection on this. In the context of midwifery, Stanley suggests that cultural learning continues well beyond placement completion as a reflective process which, "can be better facilitated through the curriculum" [41]. Echoing the constructivist approach, Sargent argues that, "cultural concepts taught in isolation of concepts about healthcare systems, power, political policy and ethics might foster thinking that reinforce stereotypes" [8]. She is however less optimistic about the potential for effective cultural brokerage in the post-placement curriculum on the grounds that, "the assumption that faculty members are more culturally competent is not supported by evidence [8]. This is an important issue that immediately relates to our earlier point about the power of authenticated stereotyping in the post-placement classroom or health facility We cannot assume that Faculty at the students' home institutions have the experience or commitment to this process at the present time.

Our decision, as an organisation managing student placements, to explicitly recognise the importance of cultural brokerage has lead to proposals to add more structure to the process from pre-placement induction, through placement exposure and post-placement reflection. This echoes the guidelines proposed by the Working Group on Ethics Guidelines for Global Health Training (WEIGHT) and reported in Crump et al. [42]. Ahluwalia et al. [43] piloted the WEIGHT guidelines in a small study of Canadian rehabilitation students on placement in LMICs. They concluded that, "achieving optimal and effective cultural learning requires a more robust and coherent pre-departure training, on-site support and where possible, mandatory post-internship de-briefing" [43].

\section{Conclusions}

By utilising the data from the three studies, this research presents a unique insight into international exposures and uncovers the impact they have on health care students in terms of their cultural learning. We conclude that the process of leaving "home", as a normalised space where we typically take things for granted, and immersing oneself in contexts where we experience discomfort, as "outsid- 
ers", presents critical opportunities for reflexive learning. Characterising these forms of learning narrowly as "cultural" has serious unintended consequences. In the first instance, it immediately indicates a narrow focus on ethnicity and religion; on learning about exotic "others" and not the mundane (ourselves). In the process, it essentialises difference legitimising rather than challenging stereotypes. The risk is that immersion, on its own, can validate such stereotypes. This interpretation of cultural learning emphasises difference at the expense of commonality. We have reviewed research which, rather than challenge the use of the term "culture", seeks to extend the concept to embrace all aspects of social differentiation and forms of inter-sectionality that describe an individual's relationship to community and welfare systems. Our findings emphasise the shared quality of (deeply contextualised) human experience whilst also reminding us of the importance of recognising and treating people as individuals. Individual experiences and needs are at once a product of their relationships with context (and the complex power dynamics defining that) and dimensions of personal agency (and individual choice). Subsuming all of this to a simplistic concept of "culture" is largely counter-productive.

Our analysis of professional and student mobilities suggests that, more often than not, when respondents talk of cultural learning, they are identifying what are, in the main, dimensions of occupational culture, rather than culture-as-ethnicity. Viewing them as such immediately draws attention to the commonality of experience across health systems and the consequences of poor accountability in public sector employment.

\section{Conflicts of Interest}

The authors declare no conflicts of interest regarding the publication of this paper.

\section{References}

[1] Royal College of Midwives (2016) Global Engagement Survey 2016. https://www.thet.org/wp-content/uploads/2018/06/THET-PowerPoint_Full.pdf

[2] Ahmed, A., Ackers-Johnson, J. and Ackers, H.L. (2017) The Ethics of Educational Healthcare Placements in Low and Middle Income Countries: First Do No Harm? Palgrave Pivot, Palgrave Macmillan, New York. https://doi.org/10.1007/978-3-319-48363-4

[3] Ackers, L., Ackers-Johnson, J., Chatwin, J. and Tyler, N. (2017) Healthcare, Frugal Innovation, and Professional Voluntarism. Springer International Publishing, Cham. https://doi.org/10.1007/978-3-319-48366-5

[4] Button, L., Green, B., Tengnah, C., Johansson, I. and Baker, C. (2005) The Impact of International Placements on Nurses Personal and Professional Lives: Literature Review. Journal of Advanced Nursing, 50, 315-324. https://doi.org/10.1111/j.1365-2648.2005.03395.x

[5] Bentley and Ellison (2017) Increasing Cultural Competence in Nursing through International Service-Learning Experiences. Nurse Educator, 32, 207-221. https://doi.org/10.1097/01.NNE.0000289385.14007.b4

[6] Latta, S., Faucher, M.A., Brown, S. and Bradshaw, M. (2011) International Clinical 
Experience for Midwifery Students. Journal of Midwifery \& Women's Health, 56, 382-387. https://doi.org/10.1111/j.1542-2011.2011.00035.x

[7] Alred, G., Byram, M. and Fleming, M. (Eds.) (2003) Intercultural Experience and Education. Multilingual Matters, Bristol, UK.

[8] Sargent Sara, E., Sedlak Carol, A. and Martsolf Donna, S. (2005) Cultural Competence among Nursing Students and Faculty. Nurse Education Today, 25, 214-221. https://doi.org/10.1016/j.nedt.2004.12.005

[9] Cunningham, P., Foster, S. and Henggeler, S. (2002) The Elusive Concept of Cultural Competence. Children's Services, 5, 231-243.

https://doi.org/10.1207/S15326918CS0503_7

[10] Leishman, J. (2004) Perspectives of Cultural Competence in Health Care. Nursing Standard, 19, 33-38.

[11] Elliott, K. (2013) Student's Corner: Providing Culturally Competent Learning Experiences for Aboriginal Students: An Undergraduate Midwife's Perspective. Contemporary Nurse, 46, 139-142. https://doi.org/10.5172/conu.2013.46.1.139

[12] Simpson, K., Smith, M. and Yanacopulos, H. (2004) Doing Development: The Gap Year, Volunteer-Tourists and a Popular Practice of Development. Journal of International Development, 16, 681-692. https://doi.org/10.1002/jid.1120

[13] Lyons, H. and Wearing, N. (2011) Gap Year Volunteer Tourism: Myths of Global Citizenship? Annals of Tourism Research, 39, 361-378.

https://doi.org/10.1016/j.annals.2011.04.016

[14] Garneau, A. and Pepin, J. (2015) Cultural Competence: A Constructivist Definition. Journal of Transcultural Nursing, 26, 9-15. https://doi.org/10.1177/1043659614541294

[15] Crenshaw, K. (1989) Demarginalizing the Intersection of Race and Sex: A Black Feminist Critique of Antidiscrimination Doctrine, Feminist Theory and Antiracist Politics. University of Chicago Legal Forum, Vol. 1989, Article 8.

[16] Fuss, D. (1989) Essentially Speaking: Feminism, Nature \& Difference. Routledge, New York, London.

[17] Anthias, F. (2008) Thinking through the Lens of Translocational Positionality: An Intersectionality Frame for Understanding Identity and Belonging. Translocations: Migration and Social Change, 4, 5-20.

[18] Valentine, G. (2007) Theorizing and Researching Intersectionality: A Challenge for Feminist Geography. Professional Geographer, 59, 10-21.

https://doi.org/10.1111/j.1467-9272.2007.00587.x

[19] Ahmed, A. (2015) Retiring to Spain: Women's Narratives of Nostalgia, Belonging and Community' Bristol. Policy Press. https://doi.org/10.2307/j.ctt1t896fb

[20] Crabtree, S., Parker, J., Azman, A. and Carlo, D. (2015) Typologies of Student Experiences and Constructed Meanings of Learning in International Placements. Asia Pacific Journal of Social Work and Development, 25, 42-53. https://doi.org/10.1080/02185385.2014.1003393

[21] Dias and Ryland (2017) Core Competencies for Health Professionals in Global Health. European Psychiatry, 41, S58. https://doi.org/10.1016/j.eurpsy.2017.01.042

[22] Esping-Andersen, G. (1989) The Three Political Economies of the Welfare State. (Special Issue: Comparative Political Economy) The Canadian Review of Sociology and Anthropology, 26, 10-36. https://doi.org/10.1111/j.1755-618X.1989.tb00411.x

[23] Gough, I. (2013) Social Policy Regimes in the Developing World. In: Kennett, P., Ed., A Handbook of Comparative Social Policy, Edward Elgar Publishing Ltd., 
Cheltenham, 205-224.

[24] Mkandawire, H. (2016) Colonial Legacies and Social Welfare Regimes in Africa. United Nations Research Institute for Social Development, Working Paper 2016-4.

[25] Ackers, H. and Ackers-Johnson, J. (2017) Mobile Professional Voluntarism and International Development Killing Me Softly?

[26] Hofstede, G. (1991) Cultures and Organisations: Software of the Mind. McGraw Hill, London.

[27] Davies, H.T.O., Nutley, S.M. and Mannion, R. (2000) Organisational Culture and Quality of Health Care. BMJ Quality \& Safety, 9, 111-119.

[28] Carney, M. (2011) Influence of Organizational Culture on Quality Healthcare Delivery. International Journal of Health Care Quality Assurance, 24, 523-539. https://doi.org/10.1108/09526861111160562

[29] Deal, T.E. and Kennedy, A.A. (1982), Corporate Cultures: The Rites and Rituals of Corporate Life. Addison-Wesley, Reading.

[30] Sarvimaki, A. and Sandelin Benko, S. (2001) Values and Evaluation in Health Care. Journal of Nursing Management, 9, 129-137. https://doi.org/10.1046/j.1365-2834.2001.00242.x

[31] West, M., Eckert, R., Collins, B. and Rachna, C. (2017) The Kings Fund, Caring to Change. How Compassionate Leadership Can Stimulate Innovation in Health Care, 3-4.

[32] Mbau, R. Gilson, L. (2018) Influence of Organisational Culture on the Implementation of Health Sector Reforms in Low- and Middle-Income Countries: A Qualitative Interpretive Review. Global Health Action, 11, Article ID: 1462579.

[33] Ackers, L., Webster, H., Mugahi, R. and Namiiro, R. (2018) What Price a Welcome? Understanding Structure Agency in the Delivery of Respectful Midwifery Care in Uganda. International Journal of Health Governance, 23, 46-59. https://doi.org/10.1108/IJHG-11-2017-0061

[34] McKay, A. and Ackers, H.L. (2013) SVP Benchmarking Report. http://www.knowledge4change.org/wp-content/uploads/2017/03/UMNH-Benchma rking-2013.pdf

[35] Voluntary Service Overseas (2002) Live Aid legacy. London.

[36] Michira, J. (2002) Images of Africa in the Western Media. https://www.researchgate.net/publication/292141961_The_Representation_of_Afric a_in_Western_Media_still_a_21st_century_problem

[37] Seay, L. and Dionne, K. (2014) The Long and Ugly Tradition of Treating Africa as a Dirty, Diseased Place.

https://www.washingtonpost.com/news/monkeycage/wp/2014/08/25/othering-ebol a-and-the-history-andpolitics-of-pointing-at-immigrants-as-potential-disease-vecto rs/

[38] Skey, M. (2011) National Belonging and Everyday Life: The Significance of Nationhood in an Uncertain World. Hampshire, Palgrave Macmillan. https://doi.org/10.1057/9780230353893

[39] Vygotsky, L.S. (1978) Mind in Society: The Development of Higher Psychological Processes. Harvard University Press, Cambridge.

[40] Tyler (2018) Examining the Learning of Health Professionals on International Placements. Unpublished Doctoral Thesis Supervised by Ackers, Ahmed and Byrne-Davis. 
[41] Stanley, D. (2014) How to Prepare for An International Elective Clinical Placement. Essentially MIDIRS, 5, 33-38.

[42] Crump, J. and Sugarman, J. (2010) Ethics and Best Practice Guidelines for Training Experiences in Global Health. The American Journal of Tropical Medicine and Hygiene, 83, 1178-1182. https://doi.org/10.4269/ajtmh.2010.10-0527

[43] Ahluwalia, P., Cameron, D., Cockburn, L., Ellwood, L., Mori, B. and Nixon, S.A. (2014) Analyzing International Clinical Education Practices for Canadian Rehabilitation Students. BMC Medical Education, 14, 187.

https://doi.org/10.1186/1472-6920-14-187 